\title{
Turbid Water Treatment Using Deshelled Carica papaya Seed: Analysis Via Factorial Design
}

\author{
Amir Hariz Amran ${ }^{1}$, Muhammad Burhanuddin Bahrodin 1,* (D), Nur Syamimi Zaidi 1,2 (D), \\ Khalida Muda 1(i), Azmi Aris 1,2 (D), Noor Azrimi Umor ${ }^{4}$, Mohd Faiz Mohd Amim 5, \\ Achmad Syafiuddin 6 (D) \\ 1 School of Civil Engineering, Faculty of Engineering, Universiti Teknologi Malaysia (UTM), 81310 Johor Bahru, Johor, \\ Malaysia \\ 2 Centre for Environmental Sustainability and Water Security (IPASA), Universiti Teknologi Malaysia, 81310 UTM \\ JohorBahru, Johor, Malaysia \\ 3 Centre for Environmental Sustainability and Water Security (IPASA), Universiti Teknologi Malaysia, 81310 UTM \\ JohorBahru, Johor, Malaysia \\ 4 Faculty of Applied Sciences, Universiti Teknologi MARA, 72000 Kuala Pilah, Negeri Sembilan, Malaysia \\ 5 Faculty of Earth Science, Universiti Malaysia Kelantan, 17600 Jeli, Kelantan, Malaysia \\ 6 Department of Public Health, Universitas Nahdlatul Ulama Surabaya, 60237 Surabaya, Indonesia \\ * Correspondence: burhanuddin1991@graduate.utm.my (M.B.B.);
}

Received: 25.09.2021; Revised: 1.11.2021; Accepted: 4.11.2021; Published: 1.12.2021

\begin{abstract}
Natural coagulants are proven to be a good alternative to conventional coagulants with the removal of various pollutants and are environmentally friendly. Despite its advantages, the least studies were carried out on local agro-wastes such as papaya seeds as natural coagulants concerning different operational factors. The study analyzes the main and interactions effect between the coagulant dosage, initial turbidity, and $\mathrm{pH}$ on deshelled Carica papaya seeds for turbid water treatment. A 2-level factorial design was used to investigate the main and interaction effects of the main operational factors, viz. coagulant dosage (50-200 mg/L), pH (3-7), and initial turbidity (100-500 NTU) on the turbidity removal of the synthetic turbid water. Based on individual performance, the results suggested that initial turbidity and $\mathrm{pH}$ are the most significant factors among the investigated operational factors. In combination, all interactions are significant, but the interaction between initial turbidity and $\mathrm{pH}$ is most significant, with 97.2\% turbidity removal. Upon application of Carica papaya seed as a natural coagulant in water and wastewater treatment, these operating variables and their interactions are best to be considered.
\end{abstract}

Keywords: 2-level factoria design; deshelled Carica papaya seeds; natural coagulant; turbidity removal.

(C) 2021 by the authors. This article is an open-access article distributed under the terms and conditions of the Creative Commons Attribution (CC BY) license (https://creativecommons.org/licenses/by/4.0/).

\section{Introduction}

, The application of simple and effective treatment methods in water and wastewater treatment is on the rise. Among many methods, one of the simple and effective treatment methods is the conventional coagulation process by using chemical coagulants such as alum and ferric chloride $\left(\mathrm{FeCl}_{3}\right)$ [1]. However, concern from using chemical coagulant arises as many researchers identify its use generates voluminous sludge with high potential of toxicity content and the chemical effect on its treated water [2-5]. Therefore, identifying other alternatives to replace conventional chemical coagulants is crucial. Many researchers have studied natural coagulants that are more environmentally friendly for water and wastewater 
treatment from various sources such as plants, animals, and algae [6]. Like chemical coagulants, natural coagulants are able to remove various pollutants such as turbidity [7], total suspended solids, color [8], and chemical oxygen demand (COD) [9] with a removal percentage of about $70 \%$ to $90 \%$. In addition, natural coagulants have better antibacterial properties compared to chemical coagulants [10]. Besides that, the natural coagulant is highly biodegradable, non-toxic, non-corrosive, and generates lesser sludge [11]. Natural coagulants as an alternative to chemical coagulants for water and wastewater treatment gain attention from many researchers with various sources such as Moringa oleifera, Opuntia ficus indica, and Jatropha curcas [12]. On top of these favorable natural coagulants, least studies on other local agro-waste such as papaya seeds were carried out. According to Pathak et al. [13], papaya seed is one of the major by-products in papaya processing, representing approximately $8.5 \%$ of the fruit weight. Since the features of the papaya seeds are the same as the Moringa oleifera and Jatropha curcas seeds, it is expected to have a promising outcome as a natural coagulant as good as a commonly studied natural coagulant.

Like the conventional coagulation process, the needs to investigate the relevant operational factors are very important to increase the effectiveness of the treatment. There are many operating variables that could affect the coagulation process, such as coagulant dosage, $\mathrm{pH}$, and initial turbidity [14]. Many studies have investigated the effect of these operating variables on water and wastewater treatment. Various methods have been explored in investigating the operational factors. Among others is the One Factor at a Time (OFAT) methodology. OFAT is a favorable approach in identification whether a factor has any effect or not [15]. However, the limitation of the OFAT is that it is unable to consider any possible interactions between the operating variables thus, inhibiting the chance to optimize the operational conditions for the best maximum treatment removal [16]. The use of experimental design such as 2-level factorial design allows trend evaluation on different operating variables on the natural coagulant. Besides trend evaluation, experimental design can also investigate not only the main effect but also the interaction effects of more than one (1) operating variables, unlike OFAT; thus, identification on reactions between operating variables that could affect turbidity removal can be identified.

Undeniably, the application of papaya seed either as coagulant aid or main coagulant was investigated by other researchers lately. However, some studies did not focus on various operating variables and their interactions. For example, Unnisa \& Bi [17] use papaya seeds as a coagulant aid to alum coupled with solar disinfection mainly for E-coli and coliform removal concerning coagulant dosage. Carica papaya seed was also used as a natural coagulant for other various pollutants such as turbidity, total dissolved solids, and total hardness with consideration to its coagulant dosage [18]. Studies by Kristianto et al. [19] and Yimer \& Dame [20] study the effect of using papaya seeds as natural coagulant concerning various operating variables such as coagulant dosage, $\mathrm{pH}$, and mixing time, but optimization was carried out without considering the significance and interactions between operating variables. Therefore, the present study aims to analyze the main and interactions effect between the coagulant dosage, initial turbidity, and $\mathrm{pH}$ on deshelled Carica papaya seeds for turbid water treatment. 


\section{Materials and Methods}

\subsection{Preparation of natural coagulant.}

This study used Carica papaya seeds as the natural coagulant. Carica papaya seeds were collected from the local market in Taman Universiti, Skudai, Johor. Upon collection, all seeds were washed by using tap water to remove any dirt on the seeds. Then, the surface membrane layer was removed by using cloth. The outer layer of Carica papaya seeds was deshelled. The deshelled Carica papaya seeds were oven-dried for 24 hours at $50^{\circ} \mathrm{C}$. By using mortar and pestle, the dried seeds were crushed to a fine powder and stored in a desiccator. In order to produce $1 \mathrm{~g} / \mathrm{L}$ of deshelled Carica papaya seeds-derived natural coagulant, $500 \mathrm{mg}$ of Carica papaya seeds were mixed with $500 \mathrm{~mL}$ distilled water [21]. Powder from Carica papaya seeds needs to be prepared again every month, while the natural coagulant stock solution needs to be prepared every day before being used.

\subsection{Preparation of synthetic turbid water.}

Synthetic turbid water in this study was prepared by using kaolin. In a beaker, mix $10 \mathrm{~g}$ of kaolin with 1L distilled water and leave for 24 hours for homogenization. After 24 hours, the sediments were removed from the solution, and the water left will be used as synthetic turbid water [22].

\subsection{Experimental design: factorial design.}

Using a 2-level factorial design, the effects of natural coagulant dosage, $\mathrm{pH}$, and initial turbidity on turbidity removal were investigated. Table 1 shows the variables and range values used in the experiments. Three (3) variables required a complete matrix of $2^{3}$, resulting in eight (8) experimental runs, and each run was conducted in duplicate; thus, sixteen (16) experiments were carried out. MINITAB software was used for the experimental design and analysis.

Table 1. Variables and range values in the experiment.

\begin{tabular}{l|c|c|c}
\multirow{2}{*}{ Variables } & \multicolumn{2}{|c|}{ Factorial } & \multirow{2}{*}{ Center point } \\
\cline { 2 - 3 } & Low & High & \\
\hline Coagulant dosage $(\mathrm{mg} / \mathrm{L})$ & 50 & 200 & 125 \\
\hline $\mathrm{pH}$ & 3 & 7 & 5 \\
\hline Initial turbidity (NTU) & 100 & 500 & 300
\end{tabular}

\subsection{Jar test.}

In $600 \mathrm{~mL}$ beaker, pour $500 \mathrm{~mL}$ synthetic turbid water with various $\mathrm{pH}$ and initial turbidity — placed beakers filled with $500 \mathrm{~mL}$ synthetic turbid water into the jar test apparatus. Various coagulant dosages were added to each beaker. The solution was mixed for 3 minutes at $250 \mathrm{rpm}$ rapid mixing and followed by 15 minutes at $30 \mathrm{rpm}$ slow mixing. After slow mixing, the solution was left for 30 minutes for the sedimentation process. For analysis of turbidity removal, water samples were collected from the surface to ensure no settled pollutants were disturbed, which could cause floc breakage. The turbidity of artificial turbid water was measured by using a turbidity meter (Milwaukee turbidimeter). Measurement of turbidity requires $10 \mathrm{~mL}$ of the water sample. The water sample was placed in a glass cuvette before being measured. Turbidity removal can be calculated using Eq. (1).

Turbidity removal $(\%)=(($ Initial turbidity - Final turbidity $) /$ Initial turbidity $) \times 100$ 


\section{Results and Discussion}

Effects of the natural coagulant dosage, $\mathrm{pH}$, and initial turbidity on turbidity removal were investigated using a 2-level factorial design. The experimental results of the factorial design analysis are given in Table 2 . The results were then statistically analyzed to determine the significance of each factor with regard to the main effects and interaction effects. The significance of each factor is based on the $p$-value. The responses obtained for this factorial design were statistically evaluated with above $95 \%$ confidence level. Operating variables for main and interaction effects with a $p$-value less than 0.05 are classified as significant. Table 3 shows the summary of the ANOVA on main, two- and three-ways interaction effects and their significance level.

Table 2. Experimental results for 2-level factorial design analysis.

\begin{tabular}{c|c|c|c} 
A: Coagulant Dosage (mg/L) & B: $\mathbf{p H}$ & $\mathbf{C}:$ Initial Turbidity (NTU) & Turbidity Removal (\%) \\
\hline 50 & 3 & 500 & 97.2 \\
\hline 200 & 7 & 100 & 2.9 \\
\hline 50 & 3 & 100 & 3.7 \\
\hline 50 & 3 & 100 & 0.0 \\
\hline 200 & 7 & 500 & 10.6 \\
\hline 50 & 3 & 500 & 97.2 \\
\hline 200 & 3 & 100 & 2.1 \\
\hline 200 & 7 & 500 & 15.1 \\
\hline 50 & 7 & 100 & 2.7 \\
\hline 200 & 7 & 100 & 2.0 \\
\hline 50 & 7 & 100 & 6.1 \\
\hline 200 & 3 & 500 & 75.5 \\
\hline 50 & 7 & 500 & 4.8 \\
\hline 200 & 3 & 100 & 11.8 \\
\hline 200 & 3 & 500 & 72.7 \\
\hline 50 & 7 & 500 & 1.2
\end{tabular}

Table 3. $p$-values of the estimated main and interaction effects of natural coagulant dosage, $\mathrm{pH}$, and initial turbidity on turbidity removal.

\begin{tabular}{c|c|c} 
Effects & p-value & Significance \\
\hline \multicolumn{3}{|c}{ Main } \\
\hline A & 0.150 & No \\
\hline B & 0.000 & Yes \\
\hline C & 0.000 & Yes \\
\hline \multicolumn{3}{c}{ 2-way interaction } \\
\hline A x B & 0.004 & Yes \\
\hline A x C & 0.032 & Yes \\
\hline B x C & 0.000 & Yes \\
\hline \multicolumn{3}{c}{ 3-way interaction } \\
\hline A x B x C & 0.000 & Yes
\end{tabular}

A: Natural coagulant dosage; $\mathrm{B}$ : $\mathrm{pH}$; $\mathrm{C}$ : Initial turbidity.

Based on Table 3, $\mathrm{pH}(\mathrm{B})$ and initial turbidity (C) shows $p$-value less than 0.05 indicates significance while coagulant dosage (A) is insignificant as the main effect. Meanwhile, the interaction between coagulant dosage and $\mathrm{pH}(\mathrm{A} \times \mathrm{B})$, coagulant dosage and initial turbidity $(\mathrm{A} \times \mathrm{C})$, and $\mathrm{pH}$ and initial turbidity $(\mathrm{B} \times \mathrm{C})$ are significant as two-way interaction effects with $p$-value $0.004,0.032$, and 0.000 respectively. A three-way interaction between coagulant dosage, $\mathrm{pH}$, and initial turbidity $(\mathrm{A} \times \mathrm{B} \times \mathrm{C})$ is significant for turbidity removal.

\subsection{Factorial analysis: main effects.}

For the turbidity removal, the indicated $p$-value as in Table 3 shows that $\mathrm{pH}$ and initial turbidity is significant as the main effect while coagulant dosage is insignificant as the main effect. The effect of coagulant dosage, $\mathrm{pH}$, and initial turbidity on turbidity removal is shown 
in Figure 1. Operating variables $\mathrm{pH}$ and initial turbidity are significant as main effects on turbidity removal, which can be seen through steep changes in turbidity removal and confirmed by a $p$-value less than 0.05 . Finding from the factorial analysis of this study is not similar to finding from other studies such as Hamidi et al. [23] and Jamshidi et al. [24]. Based on previous studies, coagulant dosage is a significant operating variable similar to $\mathrm{pH}$ and initial turbidity.

Based on Figure 1, as the $\mathrm{pH}$ increased from $\mathrm{pH} 3$ to $\mathrm{pH} 7$, the recorded turbidity removal decreased. The isoelectric point $(\mathrm{pI})$ of papaya seed is at $\mathrm{pH} 6$ [25]. At turbid water with a $\mathrm{pH}$ of less than 6 , the positively charged amino acids such as threonine, proline, and leucine can cause the papaya seeds to be positively charged natural coagulants [26]. Therefore, a positively charged natural coagulant is preferable in the removal of negatively charged colloids. A previous study by Chua et al. [27] that uses red lentils and Ayat et al. [28] that uses cactus powder as a natural coagulant also show similar findings regarding natural coagulant shows better contaminant removal at lower $\mathrm{pH}$ region. It is also worth noting that natural coagulants in water and wastewater treatment can be enhanced at extreme acidic and alkali $\mathrm{pH}$ [29]. Therefore, it is worth exploring the ability of Carica papaya seeds as a natural coagulant in extreme alkali $\mathrm{pH}$.

Besides $\mathrm{pH}$, initial turbidity is also significant as the main effect. As the initial turbidity increased from $100 \mathrm{NTU}$ to $500 \mathrm{NTU}$, the turbidity removal also increased. Abidin et al. [30] also show similar findings by using Jatropha curcas on turbidity removal. Recorded turbidity removal also increases with increasing initial turbidity from 50 NTU to 500 NTU. Finding from both studies suggest that natural coagulants can remove more turbidity in higher initial turbidity conditions. Water with higher turbidity causes more collision between coagulant and colloidal particles, thus creating more chances for the coagulant and particles to react with each other to form larger floc for gravity settlement $[31,32]$.

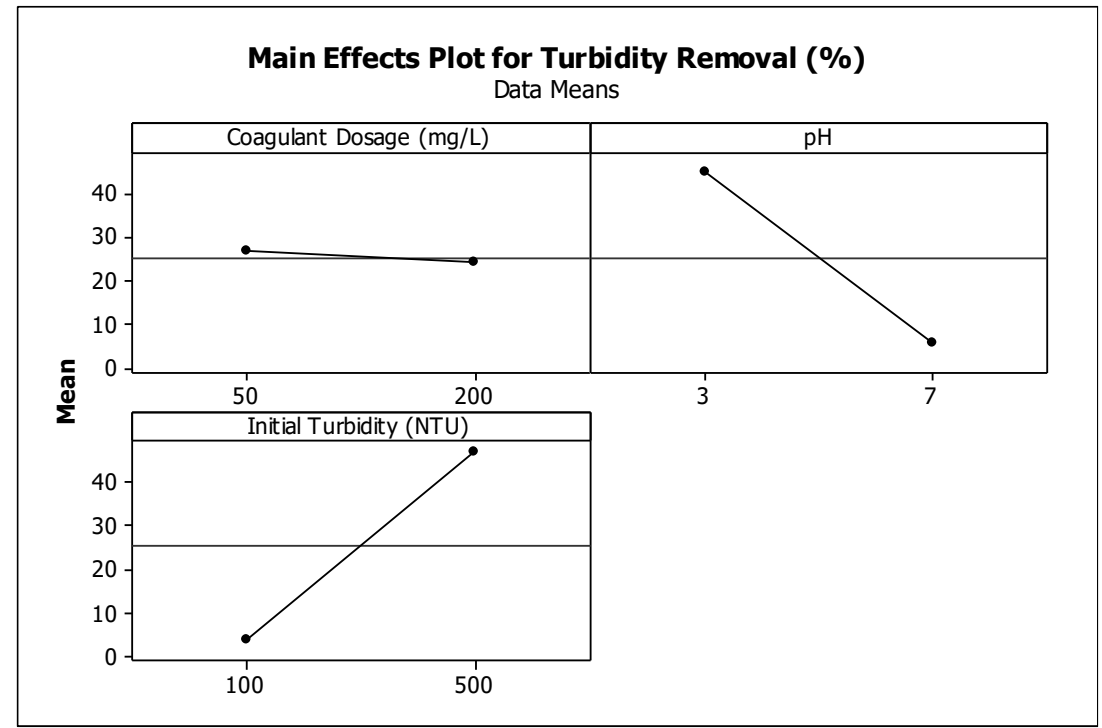

Figure 1. The main effect for turbidity removal.

\subsection{Factorial analysis: interaction effects.}

The interaction plot for the natural coagulant dosage, $\mathrm{pH}$, and initial turbidity on turbidity removal is shown in Figure 2. As summarized in Table 3, all 2-way interaction effects are significant with a $p$-value less than 0.05 . Based on Figure 2, the turbidity removal decreased as $\mathrm{pH}$ increased from $\mathrm{pH} 3$ to $\mathrm{pH} 7$ with a coagulant dosage $50 \mathrm{mg} / \mathrm{L}$. Based on a previous study, it was recorded that the isoelectric point (pI) of Carica papaya seed is at pH 6 [25]. A 
condition where $\mathrm{pH}<\mathrm{pI}(\mathrm{pH} 3<\mathrm{pH}$ 6), natural coagulant will be positively charged while $\mathrm{pH}$ $>\mathrm{pI}(\mathrm{pH} 7>\mathrm{pH}$ 6), natural coagulant will be negatively charged [26,33]. Negatively charged natural coagulants unable to form flocs as they have a similar charge with colloids. Therefore, coagulants and colloids will repel each other. With more natural coagulants from $50 \mathrm{mg} / \mathrm{L}$ to $200 \mathrm{mg} / \mathrm{L}$ would not change anything as coagulant and colloids are still unable to react, and added coagulant will only further pollute the turbid water. Kristanda et al. [34] also show similar findings where adding more coagulant dosage at unsuitable $\mathrm{pH}$ will only worsen turbidity removal as further coagulant addition can only cause previously destabilized colloids to re-stabilize.

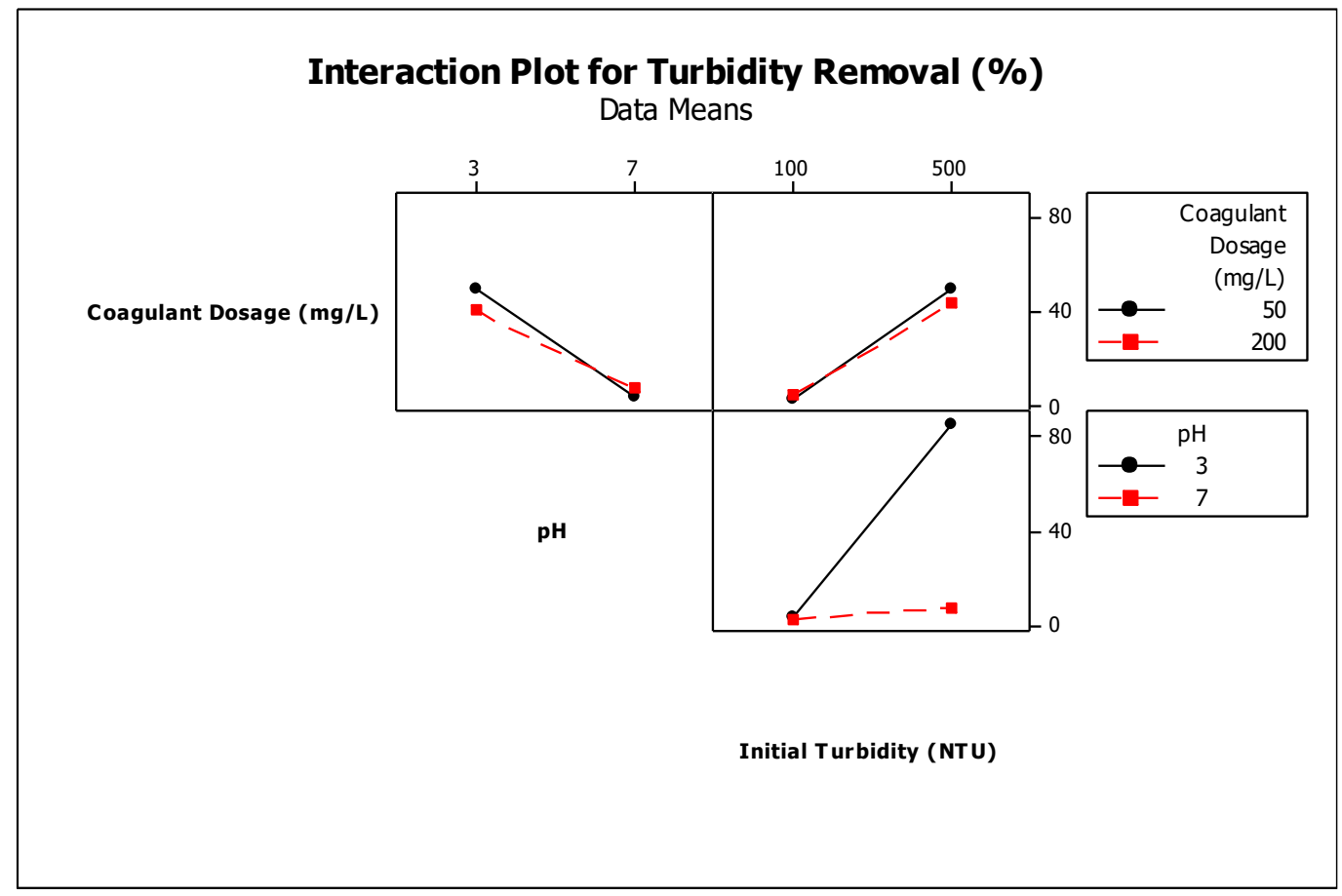

Figure 2. Interaction plot for dosage, $\mathrm{pH}$, and initial turbidity on turbidity removal.

Based on Figure 2, the interaction between coagulant dosage and initial turbidity shows that at low coagulant dosage $50 \mathrm{mg} / \mathrm{L}$ and high coagulant dosage $200 \mathrm{mg} / \mathrm{L}$, increasing initial turbidity from 100 NTU to 500 NTU will increase the turbidity removal. Water with higher initial turbidity is preferable as more collision can occur between colloids and coagulants, which encourages floc formation. Coagulant dosage as the main effect is insignificant but is significant as an interaction effect with initial turbidity. Hussain et al. [35] also show the significance of the interaction between coagulant dosage and initial turbidity. Previous and current findings validate the assumption of Okuda et al. [36] that coagulant efficiency greatly relies on coagulant dosage and initial turbidity as significant operating variables as interaction effects. However, compared to turbidity removal performance at coagulant dosage $50 \mathrm{mg} / \mathrm{L}$ and $200 \mathrm{mg} / \mathrm{L}$, lower coagulant dosage shows slightly better removal than high coagulant dosage. This shows that the high coagulant dosage supplied is excessive compared to the available turbidity. This condition is known as overdosage, where the coagulant dosage is too much compared to the pollutant that could cause the re-stabilization of colloids. Once all pollutants are removed, excess unattached coagulants contribute to turbidity instead of removing it [14, 37-38].

Besides interaction between coagulant dosage and $\mathrm{pH}$ and coagulant dosage and initial turbidity, the interaction between initial turbidity and $\mathrm{pH}$ is significant with a $p$-value less than 
0.05. At $\mathrm{pH} \mathrm{3,} \mathrm{as} \mathrm{the} \mathrm{initial} \mathrm{turbidity} \mathrm{increased} \mathrm{from} 100 \mathrm{NTU}$ to $500 \mathrm{NTU}$, the turbidity removal also increased to more than $80 \%$ removal. Previous studies using Lemna perpusilla [39] and Salvia hispanica [40] as natural coagulants also show similar findings that low $\mathrm{pH}$ and high initial turbidity can remove pollutant exceeding $80 \%$. As mentioned before, at $\mathrm{pH} 3$, papaya seed is positively charged. With higher initial turbidity, a collision between positively charged coagulants and negatively charged colloids is greater, which encourages the formation of more flocs for greater turbidity removal. However, at $\mathrm{pH} 7$, papaya seeds in negatively charged, and no flocs formation for turbidity removal as coagulants and colloids repel each other. So, further increasing initial turbidity would not cause any improvement to turbidity removal besides only worsening the water quality. Any turbidity removal recorded is probably due to the collision between colloids, but it is very low.

\section{Conclusions}

In this study, deshelled Carica papaya seeds were used as a natural coagulant for turbid water treatment, and the interactions between operating variables were investigated. There were three (3) operating variables that have been investigated for their effect on turbidity removal. The studied operating variables are coagulant dosage, $\mathrm{pH}$, and initial turbidity. For the application of deshelled Carica papaya seeds as a natural coagulant for turbid water treatment, the operating variables were modeled using a 2-level factorial design to evaluate the main and interaction effect. Based on individual performance, the results suggested that among the investigated operational factors, $\mathrm{pH}$ and initial turbidity are significant while coagulant dosage is insignificant. In combination, all 2-way interaction is significant. However, the interaction between $\mathrm{pH}$ and initial turbidity shows the highest turbidity removal, about $97.2 \%$. Upon applying Carica papaya seeds as a natural coagulant, these operating variables and their interactions are best considered. This experimental design also proves that the deshelled Carica papaya seeds perform as best as other known natural coagulants and conventional chemical coagulants. Future research on other operating variables such as mixing time and mixing speed might extend the identification of the importance of other operating variables. Once most operating variables are analyzed on their significance, the optimization process, for example, using Response Surface Methodology (RSM), can be carried out to further enhance the treatment performance in treating other pollutants such as COD, BOD, and heavy metal removals.

\section{Funding}

The authors thank Universiti Teknologi Malaysia (UTM) for the financial support provided by Research University Grant Tier 2 (Award No: 16J76) and Collaborative Research Grant (Award No: 09G79).

\section{Acknowledgments}

This research has no acknowledgment.

\section{Conflicts of Interest}

The authors declare no conflict of interest. 


\section{References}

1. Smaoui, Y.; Bouzid, J.; Ayadi, N.; Mseddi, S.; Sayadi, S. Evaluation of influence of coagulation/flocculation and Fenton oxidation with iron on landfill leachate treatment. Env. Prot. Eng. 2019, 45, 139-153.

2. Kim, A.C.; Lim, S.; Kim, Y.K. Metal ion effects on A $\beta$ and tau aggregation. Int. J. Mol. Sci. 2018, https://doi.org/10.3390/ijms19010128.

3. Zaidi, N.S.; Muda, K.; Abdul Rahman, M.A.; Sgawi, M.S.; Amran, A.H. Effectiveness of Local Waste Materials as Organic-Based Coagulant in Treating Water. IOP Conf. Ser.: Mater. Sci. and Eng. 2019a, 636, https://doi.org/10.1088/1757-899X/636/1/012007.

4. Dassanayake, K.B.; Jayasinghe, G.Y.; Surapaneni, A.; Hetherington, C. A review on alum sludge reuse with special reference to agricultural applications and future challenges. Waste Manag. 2015, 38, 321-335, https://doi.org/10.1016/j.wasman.2014.11.025.

5. Amran, A.H.; Zaidi, N.S.; Syafiuddin, A.; Zhan, L.Z.; Bahrodin, M.B.; Mehmood, M.A.; Boopathy, R. Potential of Carica papaya Seed-Derived Bio-Coagulant to Remove Turbidity from Polluted Water Assessed through Experimental and Modeling-Based Study. Appl. Sci. 2021a, 11, https://doi.org/10.3390/app11125715.

6. Kurniawan, S.B.; Abdullah, S.R.S.; Imron, M.F.; Said, N.S.M.; Ismail, N.; Izzati, H.H.A.; Othman, A.R.; Purwanti, I.F. Challenges and opportunities of biocoagulant/bioflocculant application for drinking water and wastewater treatment and its potential for sludge recovery. Intl. J. Environ. Res. Public Health 2020, 17, 133, https://doi.org/10.3390/ijerph17249312.

7. Zaidi, N.S.; Muda, K.; Loan, L.W.; Sgawi, M.S.; Abdul Rahman, M.A. Potential of Fruit Peels in Becoming Natural Coagulant for Water Treatment. Intl. J. Integr. Eng. 2019b, 11.

8. Jagaba, A.H.; Abdul Latiff, A.Z.; Umaru, I.; Abu Bakar, S. Treatment of Palm Oil Mill Effluent (POME) by Coagulation Flocculation using different Natural and Chemical Coagulants: A Review. IOSR J. Mech. Civ. Eng. 2016, 13.

9. Amran, A.H.; Zaidi, N.S.; Muda, K.; Loan, L.W. Effectiveness of Natural Coagulant in Coagulation Process: A Review. Intl. J. Eng. Tech. 2018, 7, https://doi.org/10.14419/ijet.v7i3.9.15269.

10. Saleem, M.; Bachmann, R.T. A contemporary review on plant-based coagulants for applications in water treatment. J. Ind. Eng. Chem. 2019, 72, 281-297, https://doi.org/10.1016/j.jiec.2018.12.029.

11. Chaibaksh, N.; Ahmadi, N.; Zanjanchi, M.A. Use of Plantago major L. as a Natural Coagulant for Optimized Decolorization of dye-containing wastewater. Ind. Crops Prod. 2014, 61, 169-75, https://doi.org/10.1016/j.indcrop.2014.06.056.

12. Shahimi, N.S.W.; Zaidi, N.S.; Bahrodin, M.B.; Amran, A.H. Utilization of Fruit Wastes (Jackfruit and Mango Seeds and Banana Trunk) as Natural Coagulant in Treating Municipal Wastewater. IOP Conf. Ser.: Mater. Sci. Eng. 2021, 1144, 1-10, https://doi.org/10.1088/1757-899X/1144/1/012049.

13.Pathak, P.D.; Mandavgane, S.A.; Kulkarni, B.D. Waste to Wealth: A Case Study of Papaya Peel. Waste Biomass Valori. 2018, 10, 1755-1766, https://doi.org/10.1007/s12649-017-0181-x.

14. Bahrodin, M.B.; Zaidi, N.S.; Hussein, N.; Sillanpää, M.; Prasetyo, D.D.; Syafiuddin, A. Recent Advances on Coagulation-Based Treatment of Wastewater: Transition from Chemical to Natural Coagulant. Curr. Pollut. Rep. 2021, 7, 379-391, https://doi.org/10.1007/s40726-021-00191-7.

15. Qu, X.; Wu, C.F.J. One Factor at a Time Designs of Resolution V. J. Stat. Plan. Inference 2005, 131, $407-$ 416, https://doi.org/10.1016/j.jspi.2004.03.002.

16. Akbari, S.; Mahmood, S.M.; Tan, I.M.; Adeyemi, B.J. Evaluation of One Factor at a Time (OFAT) Technique in Viscosity Modeling of Polymer Solution. J. Eng. Appl. Sci. 2017, 12, 4313-4319, https://doi.org/10.3923/jeasci.2017.4313.4319.

17. Unnisa, S.A.; Bi, S.Z. Carica papaya seeds effectiveness as coagulant and solar disinfection in removal of turbidity and coliforms. Appl. Water Sci. 2018, 8, 1-8, https://doi.org/10.1007/s13201-018-0791-X.

18. Simon, M.; Joshi, H. A review on green technologies for the rejuvenation of polluted surface water bodies: Field-scale feasibility, challenges, and future perspectives. J. Environ. Chem. Eng. 2021, 9, https://doi.org/10.1016/j.jece.2021.105763.

19. Kristianto, H.; Kurniawan, M.A.; Soetedjo, J.N.M. Utilization of Papaya Seeds as natural coagulant for synthetic textile coloring agent wastewater treatment. Int. J. Adv. Sci. Eng. Inf. Technol. 2018, 8, 2071-2077, https://doi.org/10.18517/ijaseit.8.5.3804.

20. Yimer, A.; Dame, B. Papaya seed extract as coagulant for potable water treatment in the case of Tulte River for the community of Yekuset district, Ethiopia. Environ. Chall. 2021, 4, https://doi.org/10.1016/j.envc.2021.100198.

21. Muniz, G.L.; Silva, T.C.F.D.; Borges, A.C. Assessment and optimization of the use of a novel natural coagulant (Guazuma ulmifolia) for dairy wastewater treatment. Sci. Total Environ. 2020a, 744, https://doi.org/10.1016/j.scitotenv.2020.140864.

22. Vigneshwaran, S.; Karthikeyan, P.; Sirajudheen, P.; Meenakshi, S. Optimization of sustainable chitosan/Moringa. oleifera as coagulant aid for the treatment of synthetic turbid water - A systemic study. Environ. Chem. Ecotox. 2020, 2, 132-140, https://doi.org/10.1016/j.enceco.2020.08.002.

23. Hamidi, D.; Besharati Fard, M.; Yetilmezsoy, K.; Alavi, J.; Zarei, H. Application of Orchis mascula tuber starch as a natural coagulant for oily-saline wastewater treatment: Modeling and optimization by multivariate 
adaptive regression splines method and response surface methodology. J. Environ. Chem. Eng. 2021, 9, https://doi.org/10.1016/j.jece.2020.104745.

24. Jamshidi, A.; Rezaei, S.; Hassani, G.; Firoozi, Z.; Ghaffari, H.R.; Sadeghi, H. Coagulating potential of Iranian oak (Quercus Branti) extract as a natural coagulant in turbidity removal from water. J. Environ. Health Sci. Eng. 2020, 18, 163-175, https://doi.org/10.1007/s40201-020-00449-0.

25. Amran, A.H.; Zaidi, N.S.; Muda, K.; Bahrodin, M.B.; Loan, L.W. Deshelled Carica papaya Seeds as Natural Coagulant for Improvement Quality of River Water. Sains Malaysiana 2021b, 50, 1521-1529, https://doi.org/10.17576/jsm-2021-5006-02.

26. Liang, Z.; Chen, X.; Luo, J.; Zhao, H. Bin, Yang, Z.; Zhu, J. Addition of amino acids to modulate structural, physicochemical, and digestive properties of corn starch-amino acid complexes under hydrothermal treatment. Int. J. Biol. Macromol. 2020, 160, 741-749, https://doi.org/10.1016/j.ijbiomac.2020.05.238.

27. Chua, S.C.; Malek, M.A.; Chong, F.K.; Sujarwo, W.; Ho, Y.C. Red lentil (Lens culinaris) extract as a novel natural coagulant for turbidity reduction: An evaluation, characterization and performance optimization study. Water 2019, 11, 1-19, https://doi.org/10.3390/w11081686.

28. Ayat, A.; Arris, S.; Abbaz, A.; Bencheikh-Lehocine, M.; Meniai, A.H. Application of Response Surface Methodology For Modeling and Optimization of A Bio Coagulation Process (Sewage Wastewater Treatment Plant). Environ. Manag. 2021, 67, 489-497, https://doi.org/10.1007/s00267-020-01407-0.

29. Muniz, G.L.; Borges, A.C.; Silva, T.C.F.D. Performance of natural coagulants obtained from agro-industrial wastes in dairy wastewater treatment using dissolved air flotation. J. Water Process Eng. 2020, 37, https://doi.org/10.1016/j.jwpe.2020.101453.

30. Abidin, Z.Z.; Mohd, N.M.; Madehi, N.; Sobri, S. Optimisation of a Method to Extract the Active Coagulant Agent from Jatropha Curcas Seeds for Use in Turbidity Removal. Ind. Crops Prod. 2013, 41, 319-323, https://doi.org/10.1016/j.indcrop.2012.05.003.

31.Dotto, J.; Fagundes-Klen, M.R.; Veit, M.T.; Palácio, S.M.; Bergamasco, R. Performance of different coagulants in the coagulation/flocculation process of textile wastewater. J. Clean. Prod. 2019, 208, 656-665, https://doi.org/10.1016/j.jclepro.2018.10.112.

32. Magalhães, E.R.B.; Fonseca de Menezes, N.N.; Silva, F.L.; Alves Garrido, J.W.; Angélica dos Santos Bezerra Sousa, M.; Santos, dos E.S. Effect of oil extraction on the composition, structure, and coagulant effect of Moringa oleifera seeds. J. Clean. Prod. 2021, 279, https://doi.org/10.1016/j.jclepro.2020.123902.

33. Abidin, Z. Z.; Ismail, N.; Yunus, R.; Ahamad, I.S.; Idris, A. A preliminary study on Jatropha curcas as coagulant in wastewater treatment. Environ. Technol. 2011, 32, 971-977, https://doi.org/10.1080/09593330.2010.521955.

34. Kristanda, J.; Sandrosa, K.; \& Hans, S. Optimization Study of Leucaena leucocephala Seed Extract as Natural Coagulant on Decolorization of Aqueous Congo Red Solutions. Arab. J. Sci. Eng. 2021, 46, 6275-6286, https://doi.org/10.1007/s13369-020-05008-1.

35. Hussain, S.; Ghouri, A.S.; Ahmad, A. Pine cone extract as natural coagulant for purification of turbid water. Heliyon 2019, 5, https://doi.org/10.1016/j.heliyon.2019.e01420.

36. Okuda, T.; Baes, A.U.; Nishijima, W.; Okada, M. Isolation and characterization of coagulant extracted from Moringa oleifera seed by salt solution. Water Res. 2001, 35, 405-410, https://doi.org/10.1016/S00431354(00)00290-6.

37. Bahrodin, M.B.; Zaidi, N.S.; Hussein, N.; Sillanpää, M.; Prasetyo, D.D.; Syafiuddin, A., Recent advances on coagulation-based treatment of wastewater: transition from chemical to natural coagulant. Curr. Pollut. Rep., 2021. 7, 379-391, https://doi.org/10.1007/s40726-021-00191-7.

38. Amran, A.H.; Zaidi, N.S.; Syafiuddin, A.; Zhan, L.Z.; Bahrodin, M.B.; Mehmood, M.A.; Boopathy, R., Potential of Carica papaya seed-derived bio-coagulant to remove turbidity from polluted water assessed through experimental and modeling-based study. Appl. Sci., 2021. 11, 1-15, https://doi.org/10.3390/app11125715.

39. Prihatinningtyas, E. Removal of turbidity in water treatment using natural coagulant from Lemna perpusilla. IOP Conf. Ser.: Earth Environ. Sci. 2019, 308, https://doi.org/10.1088/1755-1315/308/1/012007.

40. Tawakkoly, B.; Alizadehdakhel, A.; Dorosti, F. Evaluation of COD and turbidity removal from compost leachate wastewater using Salvia hispanica as a natural coagulant. Ind. Crops Prod. 2019, 137, 323-331, https://doi.org/10.1016/j.indcrop.2019.05.038. 